\title{
The Use of Remote Experimentation as a Teaching Tool: A Literature Review
}

\author{
J. P. Rubim, V. P. Mota, L. G. Garcia, G. L. R. Brito, and G. F. Santos
}

\begin{abstract}
This study presents data collected from a literature review published in international peer reviewed journals. It made comprehensive analysis of 99 studies published between the years 2003-2015 on the remote trial and comparison with traditional and virtual labs in the teaching and learning perspective. The sample set was selected according to keywords in six different databases, resulting in the initial survey of 579 studies. reading and compilation of articles to a final selection which resulted in 99 articles that were included in this study later was made. During the complete reading of these studies, data were collected for analysis and discussion, which allowed us to take a broad view of the advantages and disadvantages of each type of laboratory, identifying the characteristics that influence the choice of the experimental model.
\end{abstract}

Index Terms-Education learning, hands-on lab, literature review, remote experimentation, virtual laboratory, advantages and disadvantages.

\section{INTRODUCTION}

This study presents a literature review developed based on the 99 scientific papers published in international peer-reviewed journals from 2003 to 2015. A collection of relevant studies was selected aiming to obtain data from researchers conducted by authors who have implemented techniques of remote experimentation. Once the conclusions about such experiences have been extracted, an overview of both benefits and difficulties in the implementation and conduction of each laboratory can be given, considering aspects such as financial, access, infrastructure and pedagogical. This research aimed to find the characteristics that may influence the choice of a specific laboratory approach, as well as its strengths and weaknesses regarding the analyzed studies, as well as to suggest new directions for research in face of the current panorama of publications involving remote experimentation as a teaching tool, presenting the pros and cons of its implementation and usage compared to the traditional laboratory.

\section{Methodology}

The sample set was selected based on the following search

Manuscript received May 3, 2019; revised July 10, 2019

J. P. Rubim was with Federal Institute of Education, Science and Technology of Tocantins, Palmas, Brazil (e-mail: jeanepamela@gmail.com.br ).

V. P. Mota, L. G. Garcia, G. L. R. Brito, and G. F. Santos were with Federal University of Tocantins, Palmas, Brazil (e-mail: vpmota@gmail.com.br, lggarcia@uft.edu.br,_gbrito@uft.edu.br, george.f@uft.edu.br). terms: a) "Remote Experimentation" AND "Education"; b) "Remote Experimentation" AND "Knowledge"; and c) "Remote Experimentation" AND "Learning".

The databases searched were: a) ACM - Digital Library, b) Science Direct - Elsevier, c) IEEE Xplore, d) Emerald, e) Google Scholar, and f) Wiley InterScience.

To create this survey, we obeyed the following inclusion criterion:

1) works strictly related with the adopted survey subject;

2) publications in periodicals;

3) studies published in English language;

4) works published from 2003 to 2015 .

We also obeyed the following exclusion criteria:

1) repeated articles with different versions, it was included only the most complete version of the study;

2) studies that approach the theme of the remote experimentation whose focus was not the teaching and learning through remote laboratories.

The studies which returned from the search terms in the selected databases were called identified. The identified studies that apparently obeyed all the inclusion criteria and satisfied none of the exclusion criteria were selected to be downloaded to complete reading and added to this study. This search resulted, on a previous collection of data, in 579 identified studies. Posteriorly, after the application of the inclusion and exclusion criteria, we eliminated 480 articles by reading their titles or their titles and posteriorly their summaries when there were doubts, resulting in the 99 articles that were included in this survey. For the data collecting we used a table where the collected information of each one of the 99 read articles were summarized and grouped. During the complete reading of these articles, data was collected for analysis and discussion, what allowed us to have a wide view on the several aspects involving the remote experimentation. Besides that, this reading also allowed us to realize comparisons between the advantages and disadvantages of each kind of laboratory, identifying the characteristics that influence the choice between remote experimentation, virtual laboratory and traditional laboratory.

\section{DESCRIPTIVE READING OF PUBLICATIONS}

The descriptive reading of publications was made considering some parameters: definition and frequency of research methods by year and by country, list of most cited articles, evolution of publication of articles. To make this process feasible, it was necessary to filter and organize the data in order to represent in a synthetic way the relevant information referring to the 99 articles of the sample for 
creating the graphics and later description.

\section{A. Frequency of Publication by Year}

Through the graphic that show the frequency of distribution of the primary articles of this study each year from 2003 to 2015 , we can see that there was an increase in the number of publications, which reached its peak in the years 2010 and 2011. Most of these articles was found by combining the keywords Remote Experimentation AND Education using the Google Scholar database (see Fig. 1).

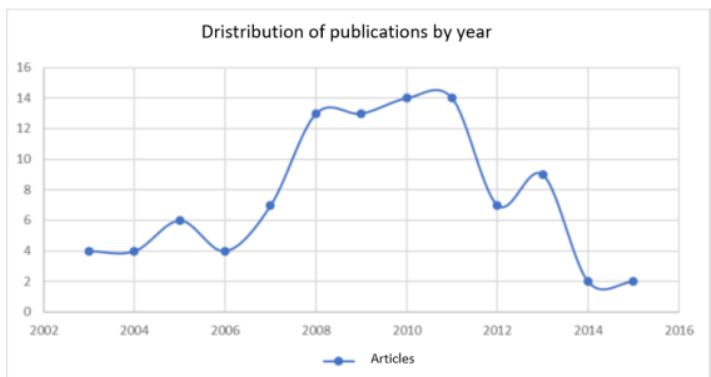

Fig. 1. Distribution of publications by year.

\section{B. Frequency of Publication by Country}

The countries that most published were the United States and Spain, which had a number of publications well above the other countries, with 21 and 16 articles respectively. In other countries, publications range from 1 to 8 articles (see Fig. 2).

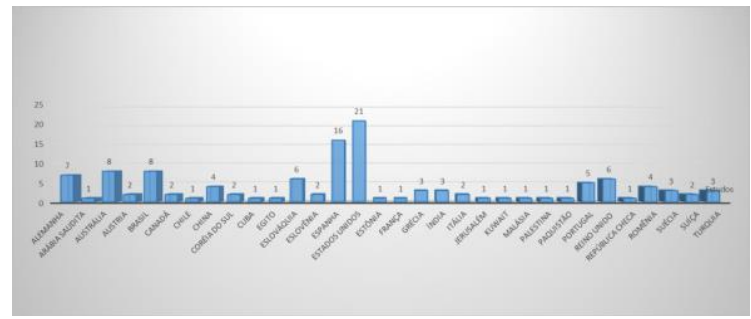

Fig. 2. Distribution of studies by country.

\section{Most Cited Articles}

Knowing the ranking in which the article is cited is important, since this information is one of the ways to know the relevance of the study in the scientific community (see Table I).

TABLE I: ARTICLES WITH OVER 50 CITATIONS (INFORMATION EXTRACTED

\begin{tabular}{|c|c|c|c|}
\hline \multicolumn{4}{|c|}{ FROM GOOGLE SCHOLAR) } \\
\hline Article & Article Title & Citation & IC \\
\hline s8o & $\begin{array}{l}\text { The Role of the Laboratory in Undergraduate Engineering } \\
\text { Education }\end{array}$ & FESE, Lyle D. and ROSA, Albert J (2005) & 729 \\
\hline s01 & $\begin{array}{l}\text { Hands-On, Simulated, and Remote Laboratories: A } \\
\text { Comparative Literature Review }\end{array}$ & MA, Jing and NCKERSON, Jeffrey $\mathrm{V}(2006)$ & 518 \\
\hline $\mathrm{S} 13$ & Control learning: present and future & BENCOMO, S. Dormido (2004) & 322 \\
\hline 560 & Ourrent Trends in Remote Laboratories & GOMES, Luis and BOGOSYAN, Seta (2009) & 231 \\
\hline s08 & $\begin{array}{l}\text { A model for evaluating the effectiveness of remote } \\
\text { engineering laboratories and simulations in education }\end{array}$ & NICKERSON, Jeffrey V. et al. (2007) & 181 \\
\hline s77 & $\begin{array}{l}\text { Laboratories in Engineering Educati } \\
\text { Simulation Lab and Remote LLa }\end{array}$ & AMURALITHARA, B. and WOODS, P. C. $(200$ & 154 \\
\hline$\$ 68$ & $\begin{array}{l}\text { Constructing Reality: A Study of Remote, Hands-On, and } \\
\text { Simulated Laboratories }\end{array}$ & CORTER, James E et al. (2007) & 146 \\
\hline s61 & $\begin{array}{l}\text { Assessment, and Use of Collaborative Remote } \\
\text { Laboratories }\end{array}$ & GUSTAVSSON, ingvar et al. (2007) & 113 \\
\hline s54 & $\begin{array}{l}\text { A Distance PLC Programming Course Enploying a Remote } \\
\text { Laboratory Based on a Fexible Manutacturing Cell }\end{array}$ & BELMUNT, Oriol Gomis et al. (2006) & 84 \\
\hline so6 & $\begin{array}{l}\text { Process and learning outcomes fromremotely-operated, } \\
\text { simulated, and hands-on student laboratories }\end{array}$ & CORTER, James E et al. (2011) & 83 \\
\hline s07 & $\begin{array}{l}\text { Remote experiments, re-versioning and re-thinking } \\
\text { science learning }\end{array}$ & SCANLON, Eleen et al. (2004) & 80 \\
\hline s27 & $\begin{array}{l}\text { The Cockpit: An Effective Metaphor for Web-based } \\
\text { Experimentation in Engineering Education }\end{array}$ & GilLet, D. et al. (2003) & 80 \\
\hline s11 & $\begin{array}{l}\text { Hands-on experiences of undergraduate students in } \\
\text { Automatics and Robotics using a virtual and remote } \\
\text { laboratory }\end{array}$ & JARA, Carlos A. et al. (2011) & 76 \\
\hline$\$ 56$ & $\begin{array}{c}\text { Assessing Student Learning in av } \\
\text { Evvironment }\end{array}$ & WOLF, Tilman (2010) & 67 \\
\hline$\$ 10$ & Developing a remote laboratory for engineering education & FABREGAS, Enesto et al. (2011) & 59 \\
\hline $\mathrm{s} 58$ & $\begin{array}{l}\text { Design, Implementation, and Evaluation of Mechatronics } \\
\text { Course }\end{array}$ & & 55 \\
\hline S84 & A Novel Approach to Remote Laboratories & DENZ, Dervis et al. (2003) & 54 \\
\hline
\end{tabular}

\section{Means of Article Publishing}

The sample of articles comes from a variety of publications, with 59 different journals, the largest being the presence of the journal Computers \& Education, which appears at first position with $8,8 \%$ of publications ( 8 of 99 ). About $60 \%$ are from journals dedicated to education (see Fig. 3).

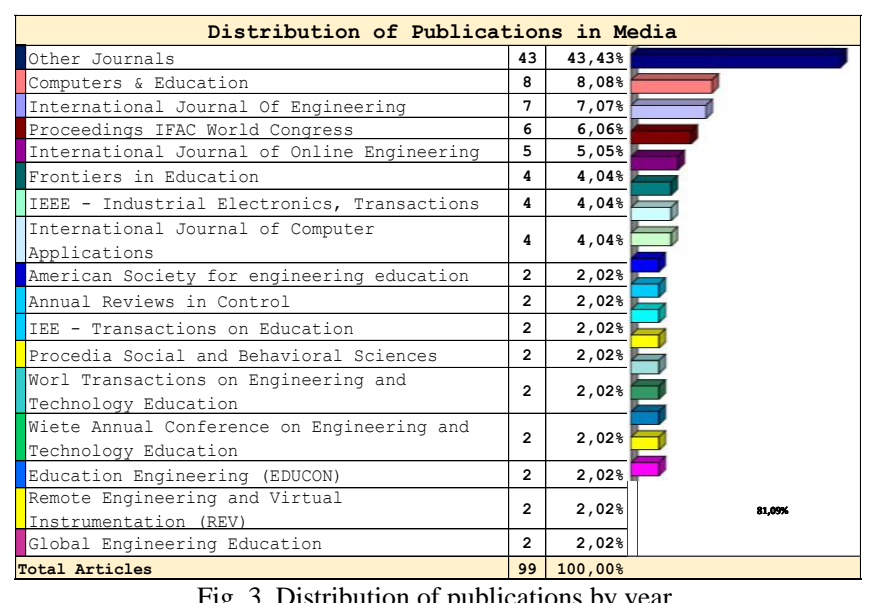

Fig. 3. Distribution of publications by year.

\section{E. Research Area with the Highest Concentration of} Articles about Remote Experimentation

Data analysis indicates that the large area "Engineering" is the one with the most articles (59), followed by the area of Natural Sciences, Mathematics and its Technologies (26) that integrate Biology, Physics, Chemistry and Mathematics in the same area of knowledge (see Fig. 4).

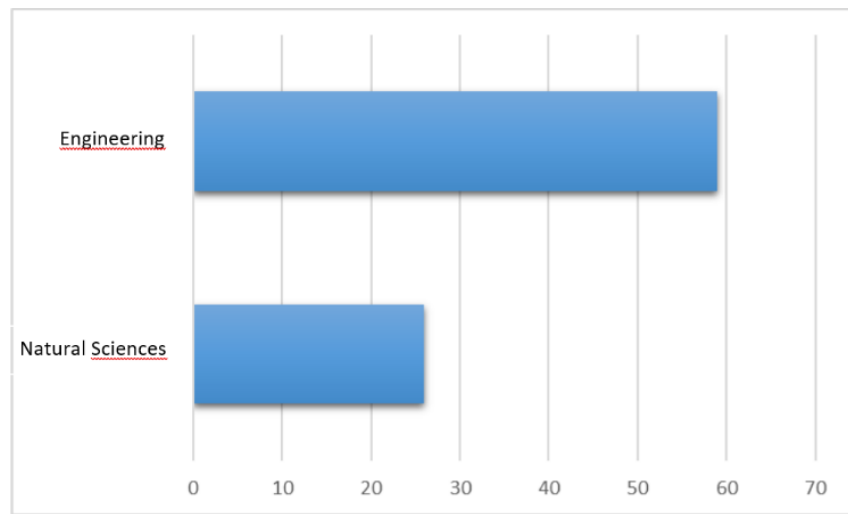

Fig. 4. Number of articles by area of knowledge.

In addition to these there is also Computer Science (2). It is important to note that some studies explicitly cite the subareas of knowledge they refer to, while others only mention the large area such as engineering or nature sciences. The subareas of the great Engineering area that presented studies were: Electrical Engineering: (26), Mechanical Engineering: (6), Mechatronics Engineering: (5), Computer Engineering: (2), and Civil Engineering: (1).

\section{RESUlts}

Our results summarized the main technologies used by the authors of the selected articles as well as the interactions between Client and Server environments and the advantages and disadvantages of remote experimentation over traditional experimentation (see Fig. 5). 


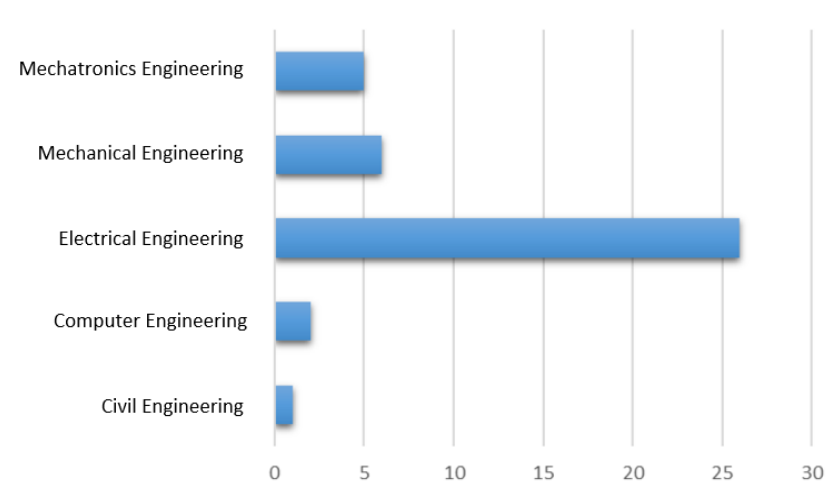

Fig. 5. Distribution of the number of articles in the engineering subareas.

\section{A. Client and Server Environment on Remote Experimentation}

Our study also pointed which the main Technologies are involved with the Server and Client environments, and their most common combinations. In the case of the Server environment, the most used Technologies are: LabVIEW, Matlab/Simulink, Java, NetLAB, and Perl. Another Server environment responsibility is the availability of a virtual learning environment (or e-learning environment). The surveys indicate that the most commonly used Technologies to create this learning environment form the combination PHP/MySQL (see Fig. 6).

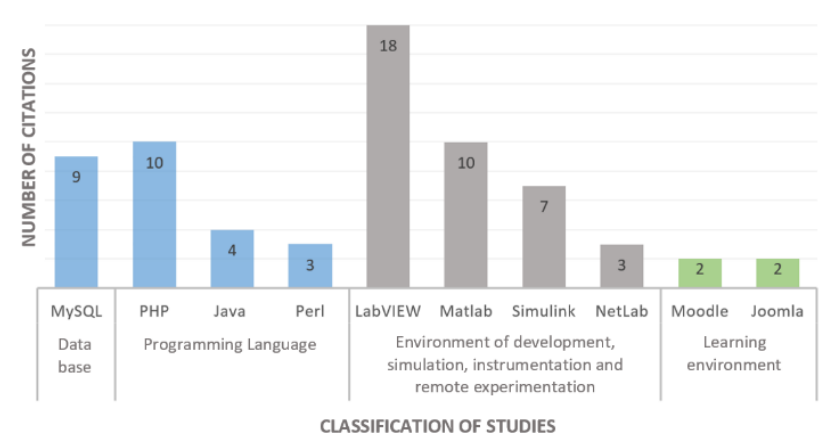

Fig. 6. Frequency of use of server technologies.

In the case of the Client environment, the most used technologies were: Java Applets, HTML, Microsoft Silverlight, VRML and Java Script. The most common technology combinations Server/Client were: LabView and Java Applets, Matlab/Simulink and Java Applets, PHP/MySQL and HTML, LabView and Microsoft Silverlight (see Fig. 7).

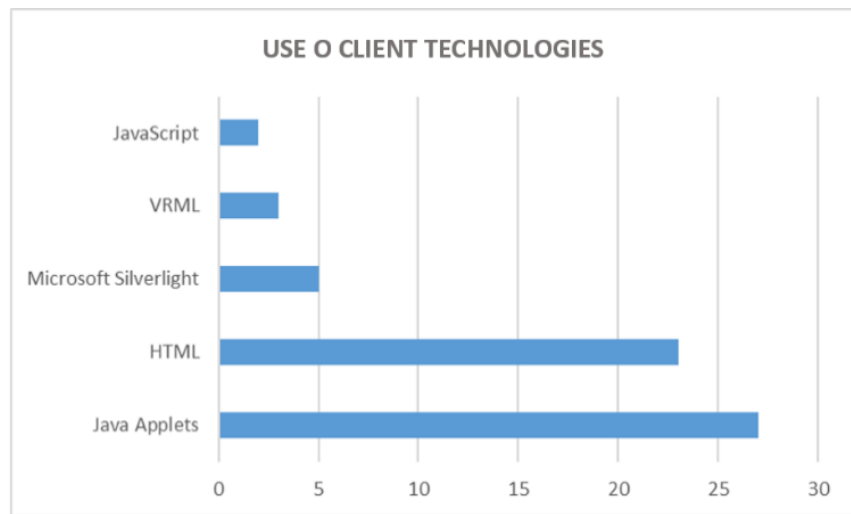

Fig. 7. Frequency of use of client technologies.

\section{B. Interaction between Client and Server Technologies}

Beyond to observing how the researches use each technology client and server individually, it was also possible to find a usage pattern that allows to identify which client and server technologies are most frequently used together. The result of this analysis shows the connection between the Client and Server technologies used in the articles. In the graph, the thickness of an edge is directly proportional to the frequency of use of two technologies (demonstrated by the Fig. 8).

We can also identify Adobe Flash, which is a virtual machine used to execute SWF files (or Flash files), as a technology that offers recurrent support to illustrate the interactions that occur in the laboratory, assisting the client in visualizing the experiment. In addition, many remote experiments are accompanied by the simulation of the experimental process in order to become more didactic to the student and in this case, the use of Flash is frequent.

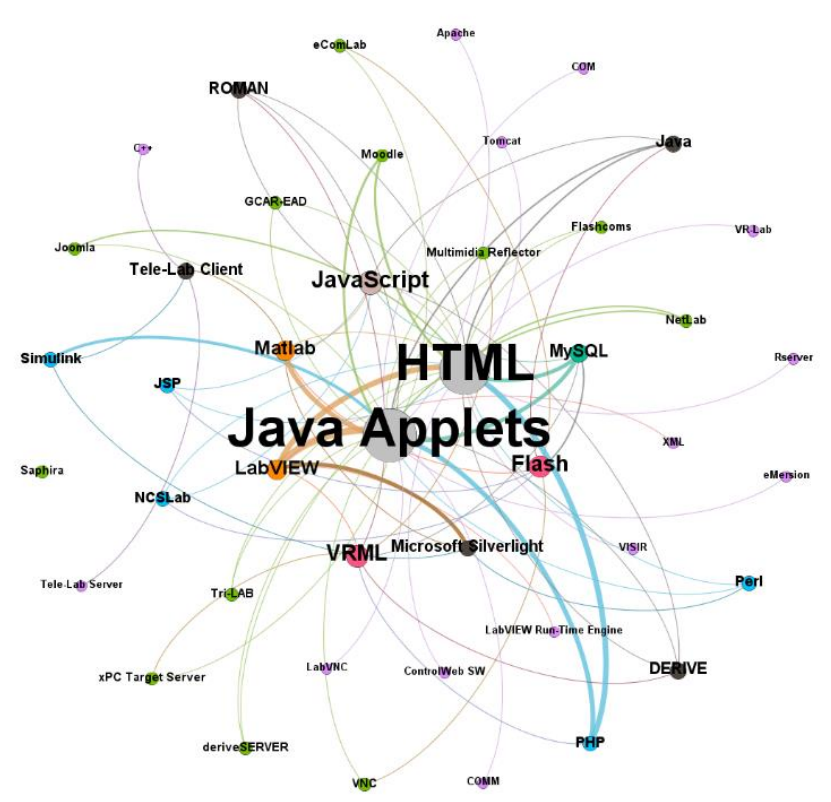

Fig. 8. Relationship between client and server technologies.

\section{The Advantages and Disadvantages of the Remote Experimentation in the Teaching Process}

According to our studies we listed several advantages and disadvantages of the remote experimentation laboratory in relation to the traditional laboratory. Regarding the resources sharing the remote laboratory represents an advantage over the traditional laboratory, considering the fact that the different educational institutions, often very distant from each other, may use the same equipment [1]. With regard to the instructor's supervision during the equipment use, the remote laboratory also represents advantage over the traditional laboratory, considering the fact that the first does not demand constant supervision to the learner's realizing experiments with safety [1]. With regard to the equipment access ways, the remote experimentation laboratory also represents advantage over the traditional laboratory, considering the fact that the first one allows $24 / 7$ access from everywhere, besides making possible the experimentation achievement in learner restricted access laboratories [1]. Yet, 
the remote experimentation laboratory facilitates the disabled and reduced mobility learner access, who can realize the experiment in his or her house [2]. With regard to the physical space demand, the remote experimentation laboratory represents advantage over the traditional laboratory, considering the fact that the physical space necessity in the first case is quite smaller due to the inexistence of learner's flow in its installations [3]. With regard to the learner safety, the remote experimentation laboratory represents advantage over the hands-on labs, considering the fact that the first one ensures safety to the learner in case of experiments involving high voltage, radiation, etc. [2]. With regard to collaborative work realization, the remote experimentation laboratory represents advantage over the hands-on labs, considering the fact that the communication tools of the first one offer perspectives of teaching scenery formation close to teamwork practice involving learners from different locations [2]. With regard to the manipulation of real equipment, the remote experimentation laboratory represents disadvantage over the hands-on labs, considering the fact that in the first one the learner doesn't have direct contact with the equipment [1]. With regard to the implantation, the remote experimentation laboratory represents disadvantage over the hands-on labs, considering the fact that the first one usually needs high-speed broadband limiting its applicability precisely where it is made more necessary [4]. Besides, the remote experimentation laboratory demands the presence of a specialized and interdisciplinary Professional team for its implementation. It happens due to the common difficulties associated to the planning, design of systems and equipment operation [1]. In relation to the acquisition and installation initial cost, the remote and virtual laboratories are disadvantageous in relation to the hands-on labs. However, it is considered the resources sharing, the laboratory equipment availability time, the lack of an instructor physical presence necessity, and the equipment protection regarding the bad use by the learners that could damage it, this high initial investment is perfectly justified [1]. Lastly, several primary studies suggest that the learning results reached by the learners are the same or superior in the remote experimentation laboratory comparing to the hands-on labs in all learning outcome categories (knowledge and understanding, inquiry skills, practical skills, perception, analytical skills, and social and scientific communication) [5] (see Fig. 9).

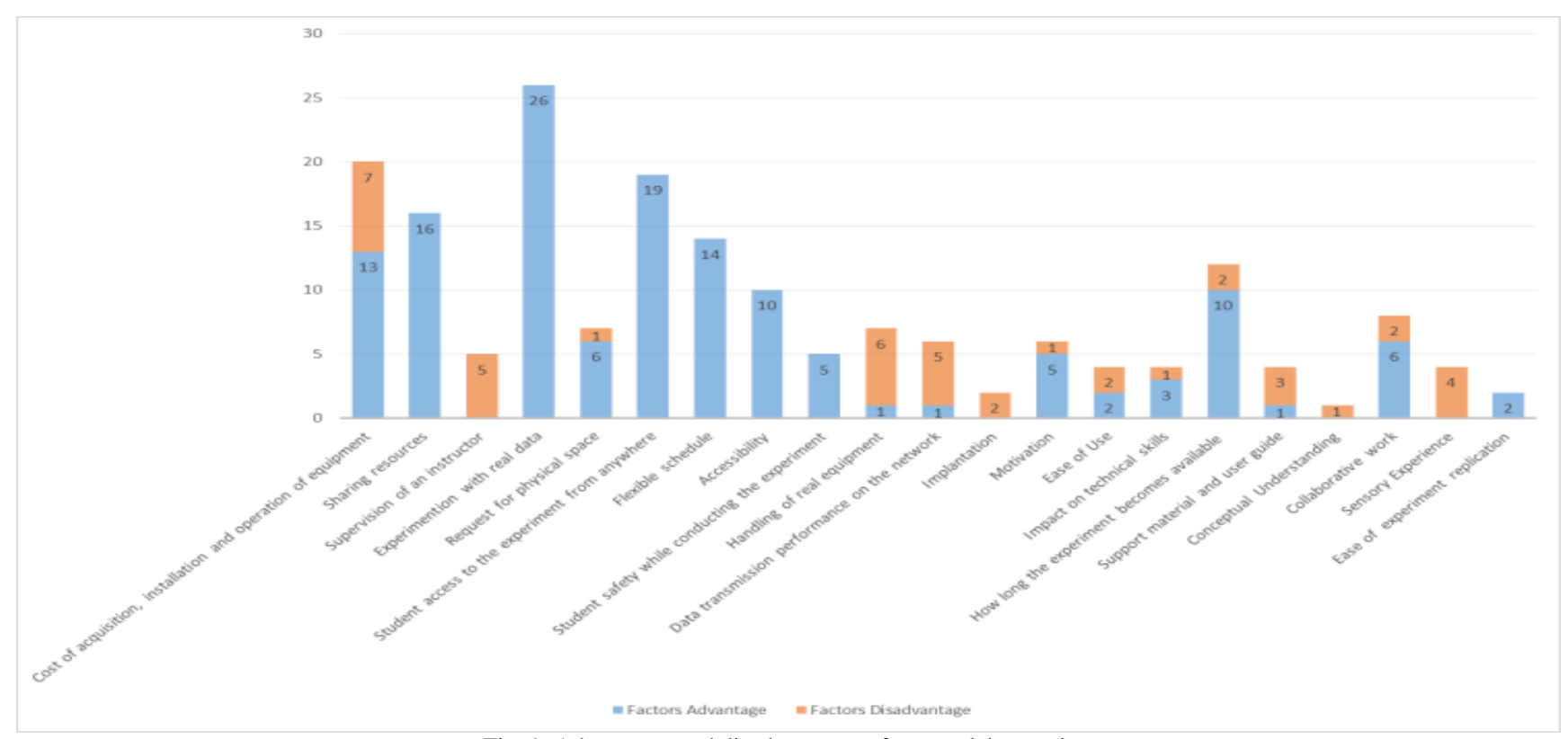

Fig. 9. Advantages and disadvantages of remote laboratories.

\section{CONCLUSION AND LIMITATION}

Technologies have been identified that can be considered as an alternative in the implementation of remote laboratories We found that, on the server side, for this article sample, the most used is LabView. The preference for this object-oriented programming language for graphic development, according to the studies included in this research that adopted it, is to be available to a wide variety of computer systems and to be a complete and user-friendly language. In client technology, studies indicate a higher frequency of Java applets, justified by the interacting subjects mainly because of their characteristics: operating system independence, since it is executed by a virtual machine called JVM (Java Virtual Machine), and popularity. Although there are many adepts at the use of remote laboratories and simulations, they still do not replace hands-on experiments. Thus, many researchers recognize that the mixed approach can be a viable alternative in the construction of practical knowledge through laboratories [6]. This study contributes to identifying the positives and negatives of each experimental approach by comparing them, not to say which ones stand out, but in which they diverge, and how their differences can expose criteria that determine the choice of the experimental teaching modality that is most appropriate the reality of the educational institution, its teachers and students. There are many high-quality articles that were not found in the search process adopted in this study, so the articles included in this research should be considered as a representative number of publications on the subject, never in their entirety. In the research, many other articles were read that are not among the 99 included, however, they are being cited as a reference. 
There is still much to be explored about the relationship between remote experimentation and the teaching and learning process. It is not possible to say, for example, that remote experimentation can replace traditional laboratories. However, the direction of research points to the use of remote laboratories as a means of inclusion, as an alternative for those whose access to experimentation is restricted, often non-existent or even as a complement to the activities performed in hands-on laboratories. This study contributes to identifying the positives and negatives of each experimental approach by comparing them, not to say which ones stand out but in which they diverge, and how their differences can expose criteria that determine the choice of the experimental teaching modality that is most appropriate the reality of the educational institution, its teachers and students. As a future study, we suggest associating the results of this research with a survey among learners who participate in the laboratory modalities mentioned in this study, considering the identified characteristics, tracing parameters that allow the evaluation of the students' experience in each laboratory.

\section{CONFLICT OF INTEREST}

We authors of the paper "The use of remote experimentation as a teaching tool: a literature review" declare no conflict of interest.

We also declare that there are no commercial, political or financial interests on the part of the authors in this manuscript, being only academic disclosure. We also declare that all financial and material support for this research is stated in the manuscript.

\section{AUTHOR CONTRIBUTIONS}

\begin{tabular}{|l|l|}
\hline \multicolumn{1}{|c|}{ Task } & \multicolumn{1}{c|}{ Authors } \\
\hline Define the research project & $\begin{array}{l}\text { J. P. Rubim, L. G. Garcia, G.L.R. Brito, G. F. } \\
\text { Santos }\end{array}$ \\
\hline Collect and analyze data & J. P. Rubim, V. P. Mota \\
\hline Wrote the paper & J. P. Rubim, V. P. Mota, L. G. Garcia \\
\hline Review and improve & L. G. Garcia, G.L.R. Brito, G. F. Santos \\
\hline
\end{tabular}

All authors had approved the final version.

\section{REFERENCES}

[1] M. Abdulwahed and Z. K. Nagy, "The TriLab, a novel ICT based triple access mode laboratory education model," Comput. Educ., vol. 56, no. 1, pp. 262-274

[2] J. R. Brinson, "Learning outcome achievement in non-traditional (virtual and remote) versus traditional (hands-on) laboratories," Comput. Educ., vol. 87, no. C, pp. 218-237, 2015.

[3] J. E. Corter et al., "Process and learning outcomes from remotely-operated, simulated, and hands-on student laboratories," Comput. Educ., vol. 57, no. 3, pp. 2054-2067, 2011.

[4] D. Popescu et al., "Remote vs. simulated, virtual or real-time automation laboratory," in Proc. 2009 IEEE International Conference on Automation and Logistics, pp. 1410-1415, 2009.

[5] J. Ma and J. V. Nickerson, "Hands-on, simulated, and remote laboratories," CSUR, vol. 38, no. 3, 2006.
[6] G. Olympiou and Z. C. Zacharia, "Blending physical and virtual manipulatives: An effort to improve students' conceptual understanding through science laboratory experimentation," Science Education, vol. 96, no. 1, pp. 21-47, 2012.

Copyright (C) 2019 by the authors. This is an open access article distributed under the Creative Commons Attribution License which permits unrestricted use, distribution, and reproduction in any medium, provided the original work is properly cited (CC BY 4.0).

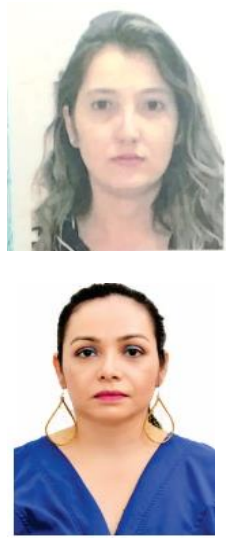

Jeane P. Rubim was born in Paraíso do Tocantins, Tocantins, Brazil on June 24, 1986. She was graduated in information systems in 2009 and has a master's degree in computational modeling of systems by the Federal University of Tocantins, Brazil since 2016. She worked as administrative technician in education at the Federal Institute of Tocantins, Palmas. database, management and control of telephony fixed cabling, structured cabling, team management and improvements.

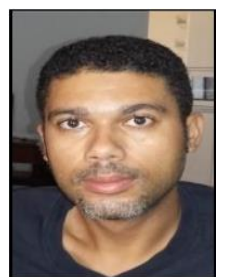

Leandro G. Garcia was born in the state of Goiás (Brazil) in 1978. He has a bachelor's degree in biomedicine from the Federal University of São Paulo (Brazil) and finished his doctorate in cell and molecular biology in the University of Brasilia (Brazil) in 2006.

He worked as teacher and coordinator of the biomedicine undergraduate course of Faculty of Higher Educations of the United Amazon (FESAR) and currently is an associate professor at the Federal University of Tocantins. In the university he works developing ELVs for embryology, parasitology and human anatomy teaching. Currently he also works with research and development in the field of health computing.

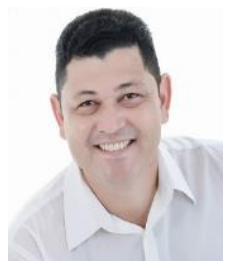

George L. R. de Brito is associate professor at the Federal University of Tocantins - UFT in the bachelor's degree in computer science, in the degree in informatics - PARFOR and in the master's program in computational modeling of systems; the bachelor in electrical engineering - UFMT, specialist in public management - UFT, the master in electrical engineering - USP, the doctor of electrical engineering - UnB. His research interests are systems modeling, educational technologies, applied informatics, legal informatics.

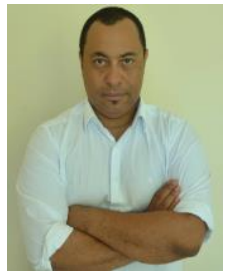

George F dos Santos is adjunct professor of the Federal University of Tocantins UFT in the course of: Libras and in the post graduate program in computational modeling of systems - PPGMCS. He got the doctor of education: curriculum from the Pontifical Catholic University of São Paulo. He graduated in philosophy from Federal University of Santa Catarina UFSC. He got the master in production engineering and systems: media and knowledge from the same University. He develops teaching, research and extension activities in the area of educational technologies, distance education and philosophy of education. 